\title{
Multicentric paraspinal neuroglial heterotopia with Müllerian and renal agenesis: a variant of Mayer-Rokitansky-Küster-Hauser syndrome?
}

\author{
Lu-Hau Deng ${ }^{1}$ and Chii-Hong Lee 2* $^{*}$
}

\begin{abstract}
Neuroglial heterotopia is a rare congenital anomaly that mostly involves the head and neck region. We report a female fetus with multicentric paraspinal neuroglial heterotopia in the retropharyngeal and retroperitoneal spaces, right renal agenesis, left renal hypoplasia, and Müllerian agenesis. Additional findings included bilateral preaxial polydactyly of the hands, megacystis, rectovesical fistula, and imperforate anus. The karyotype was $46, X X$. This fetus had the features of Mayer-Rokitansky-Küster-Hauser (MRKH) syndrome with paraspinal neuroglial heterotopia. This is the first report of the co-occurrence of these two malformations which could share a common pathogenetic mechanism. We suggest this to be a variant MRKH syndrome.

Virtual slides: The virtual slide(s) for this article can be found here: http://www.diagnosticpathology.diagnomx.eu/ vs/3246922721015286.
\end{abstract}

Keywords: Neuroglial heterotopia, Müllerian agenesis, Renal agenesis, Mayer-Rokitansky-Küster-Hauser syndrome, Pathogenesis

\section{Introduction}

Neuroglial heterotopia is a rare congenital anomaly that is probably related to neural tube defects [1-4]. It mostly affects the head and neck region, especially the nasal cavity. Only a few cases have been reported at other sites, such as the lungs [5] and retroperitoneum [2,6,7]. Multicentricity is exceptional [5], and concomitant congenital anomalies have not been reported in English literature. Here we present an unusual case of multicentric neuroglial heterotopia involving the retroperitoneal and retropharyngeal spaces accompanied by Müllerian agenesis, bilateral ovarian agenesis, right renal agenesis, left renal hypoplasia, rectovesical fistula, imperforate anus, and polydactyly.

\section{Case report}

A 26-year-old female received regular prenatal care at our obstetric department during her second pregnancy. Oligohydramnios and fetal megacystis were detected by

\footnotetext{
* Correspondence: b8301130@tmu.edu.tw

2Department of Pathology, Taipei Medical University-Shuang Ho Hospital, 291, Zhongzheng Road, Zhonghe District, New Taipei City 23561, Taiwan Full list of author information is available at the end of the article
}

routine ultrasound at the 14th week of gestation. An amniocentesis test revealed a normal female 46, XX karyotype. The mother decided to terminate the pregnancy.

At autopsy, the female fetus weighed $85 \mathrm{~g}$, and the crown-rump length was $12.2 \mathrm{~cm}$. External examination revealed a typical phenotype of Potter sequence. Bilateral preaxial polydactyly of the hands was also noted. Internal examination revealed a disproportionately large urinary bladder, measuring $2.4 \times 1.7 \times 0.6 \mathrm{~cm}$, accompanied by a rectovesical fistula and imperforate anus (Figure 1A). The left kidney was very small and weighed $0.02 \mathrm{~g}$. The right kidney and bilateral ureters were not found. The bilateral ovaries and the müllerian structures, including the fallopian tubes, uterus, and vagina, were absent (Figure 1B). A white, soft and partially liquefied mass $(2.8 \times 2.2 \mathrm{~cm})$ was found in the retroperitoneum (Figure 1A, 1B \& 1D). Another mass $(1.5 \times 1 \mathrm{~cm})$ with a similar gross appearance was identified in the retropharyngeal space (Figure 1C \& 1D). The cranium and vertebral column were intact. No evidence of dorsal or ventral dysraphism or craniofacial defect was found. The leptomeninges were intact. The gross appearance of the brain and spinal cord was normal with autolysis. 

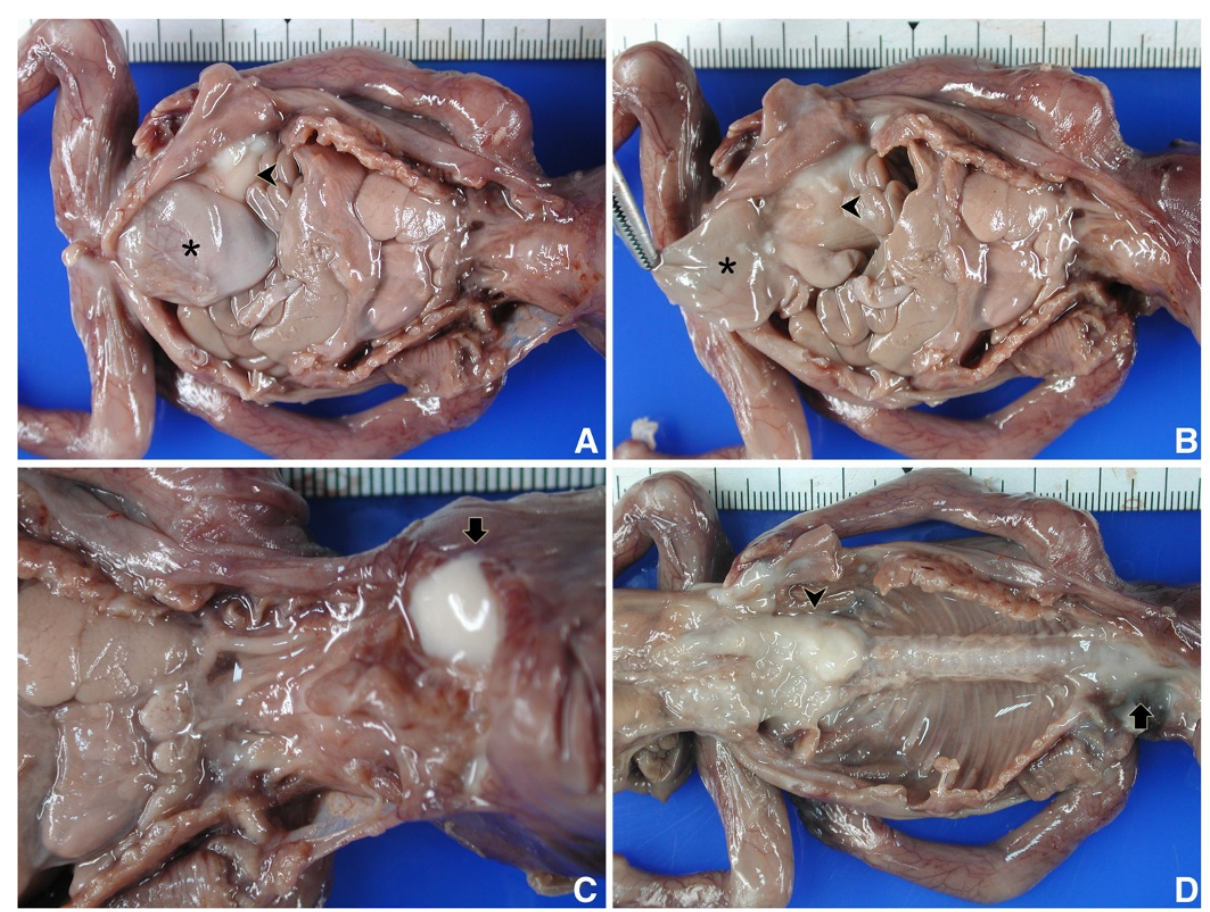

Figure 1 Internal examination in autopsy. (A \& B) Megacystis (asterisk), retroperitoneal neuroglial heterotopia (arrowhead), and uterine agenesis. (C) Retropharyngeal neuroglial heterotopia with autolysis (arrow). (D) Partially liquefied retroperitoneal and retropharyngeal neuroglial heterotopia after evisceration.
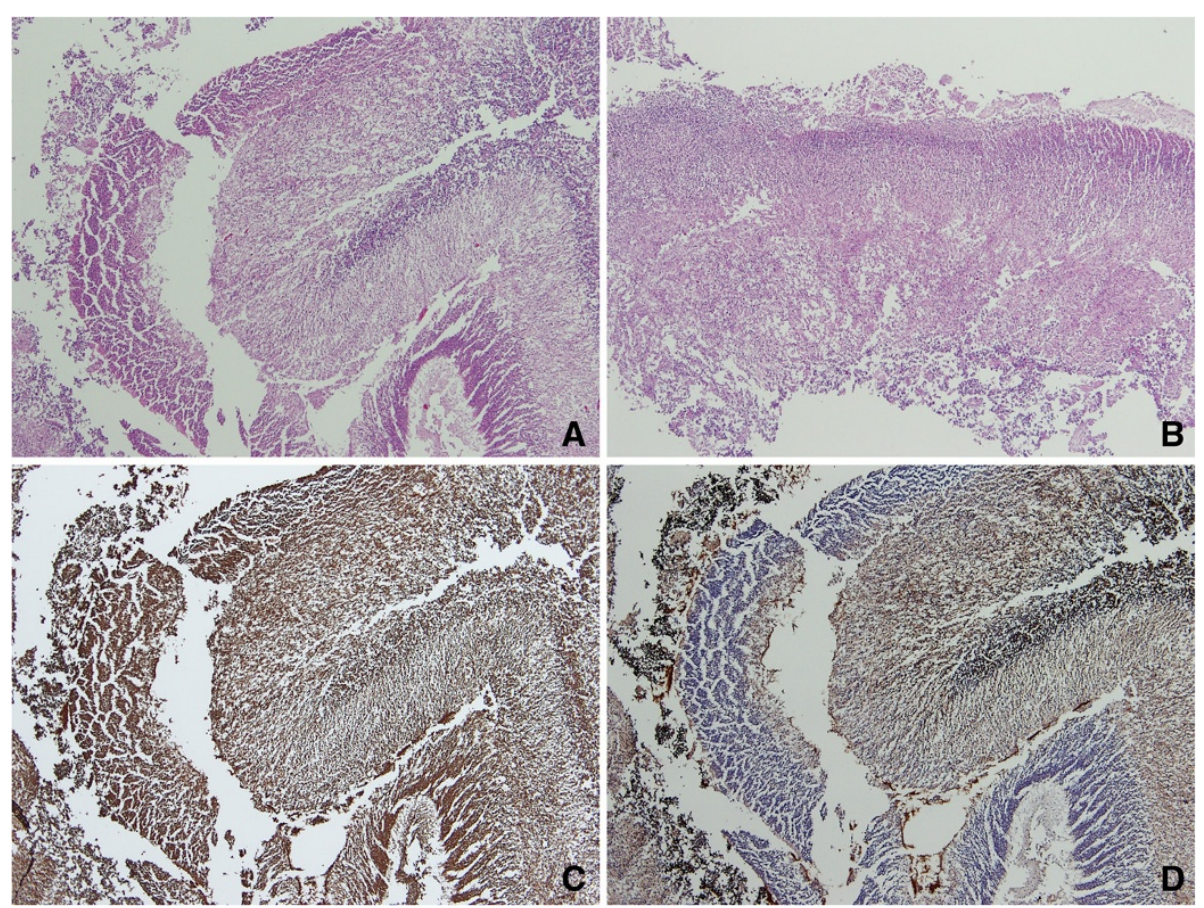

Figure 2 Microscopic features of neuroglial heterotopia. The retroperitoneal (A) and retropharyngeal (B) masses were composed of cellular cortical plate and hypocellular white matter. Both the cortical plate and the white matter were reactive for NSE (C) and the latter was also reactive for GFAP (D) 
Histologically, both masses were composed of autolysed neuroglial tissue characterized by layers of cellular cortical plate and hypocellular white matter, resembling normal fetal cerebral tissue (Figure 2A \& 2B). Both the cortical plate and the white matter show positive immunoreactivity for CD56 and neuron-specific enolase (NSE) (Figure 2C). The glial tissue of the white matter was also positive for glial fibrillary acidic protein (GFAP) (Figure 2D). No other ectodermal, mesodermal or endodermal derivative was observed.

\section{Discussion}

Heterotopia, or choristoma, is applied to aggregates of normally formed tissues that are present in aberrant anatomical locations. Examples of heterotopias include a patch of gastric mucosa in the upper third of the esophagus, a rest of pancreatic tissue in the gastrointestinal wall, or a parathyroid gland within the thymus in the anterior mediastium. Heterotopia is usually an incidental finding, but it can be confused clinically with a neoplasm. In exceptional cases, true neoplasms may arise from heterotopic tissues $[8,9]$.

Neuroglial heterotopia is a rare developmental anomaly with a rich variety of clinical features, pathological findings, and pathogenetic mechanisms. Based on anatomical location and pathological differentiation, Hori et al. proposed a classification of neuroglial heterotopia into extraneuraxial and paraneuraxial groups [2]. Extraneuraxial neuroglial heterotopia is much more common and usually involves the nasal cavity or the superficial soft tissue of the head and neck. Pathologically, it is characterized by a disorganized mixture of neuroglial and mesenchymal tissues or a lump of organized neural tissue similar to normal brain histology. It is often obvious at birth but may remain asymptomatic until late childhood or even adulthood. Complete surgical excision is curative in most cases $[1,3,10,11]$. On the other hand, paraneuraxial neuroglial heterotopia is rare and may involve the paracranial or paraspinal spaces, such as the occipital bone, retroperitoneum, and deep neck. It is composed of organized brain tissue and is usually diagnosed shortly after delivery or in early childhood. Disease-related complications are common $[2,6,7,12,13]$.

The pathogenesis of neuroglial heterotopia is uncertain. Several pathogenetic hypotheses of extraneuraxial neuroglial heterotopia have been proposed, including (1) herniation of neuroectodermal tissue through a primary bony defect that is followed by a partial or complete secondary closure resulting in sequestration of the herniated tissue [1,3]; (2) separation and detachment of cerebral precursors (which later mature ectopically) from the brain primordium in early embryogenesis [1,12]; (3) aberrant migration of pluripotential embryonic tissue with subsequent neuroglial differentiation [1]; (4) retention of neuroectodermal remnants [14]; and (5) teratoma formation with a predominant or exclusive neuroglial component [1]. However, no single hypothesis can completely explain all the varieties of extraneuraxial neuroglial heterotopia. In contrast, paraneuraxial neuroglial heterotopia is closely related to neural tube defects, such as encephalocele and myelomeningocele. For instance, paraneuraxial neuroglial heterotopia shares a similar anatomical distribution and histological features with encephalocele and myelomeningocele $[2,5-7,12,13]$. A connection between the heterotopic neuroglial tissue and the intervertebral region via a string of connective tissue is found in some cases, and this gross picture is not much different from that of a myelomeningocele with an obliterated connection to the spinal cord $[2,6]$. Accordingly, the "herniation and sequestration" hypothesis seems tenable to explain the pathogenesis of paraneuraxial neuroglial heterotopia. The process of "herniation and sequestration" acts like a mild or "partially corrected" version of neural tube defects. This is probably why concomitant congenital anomaly is far less frequent in paraneuraxial neuroglial heterotopia than in encephalocele and myelomeningocele.

In this report, we present a case of multifocal paraneuraxial, paraspinal neuroglial heterotopia concomitant with congenital anomalies associated with Mayer-Rokitansky-Küster-Hauser (MRKH) syndrome. MRKH syndrome is regarded as an inhibitory malformation of the Müllerian ducts. It is characterized by agenesis of the uterus and the upper two-thirds of the vagina in individuals with a normal female karyotype $[15,16]$. Associated anomalies of the renal, skeletal and cardiovascular systems are present in about half of cases, and this severe form of the disease is categorized as atypical MRKH or MURCS association $[15,16]$. Ovarian agenesis, imperforated anus, polydactyly, and encephalocele have also been reported [15-18]. Although the pathogenesis of MRKH syndrome remains unclear, it is suggested that the spectrum of anomalies are attributed to the extent of developmental field defects that primarily affect the fetal mesoderm or its progenitor tissue in early embryogenesis [16]. When such mesodermal defects involve the paraaxial mesoderm, encephalocele, myelomeningocele and paraneuraxial neuroglial heterotopia may develop [1,3,19]. Given the similarity of the pathogenetic hypotheses for paraspinal neuroglial heterotopia and Müllerian agenesis, we suggest that the present case constitutes an unusual variant of MRKH syndrome.

\section{Consent}

Written informed consent was obtained from the parent of the fetus for the use of the images and case presentation for educational and scientific purposes provided the unique personal identification is not revealed. 


\section{Competing interests}

Both authors declare that they have no competing interests.

\section{Authors' contributions}

LHD prepared this case report and literature review. CHL is the attending pathologist who performed the autopsy, made the diagnosis and finalized the manuscript. Both authors read and approved the final manuscript.

\section{Author details}

'Department of Pathology, Taipei Medical University-Wan Fang Hospital, 111, Section 3, Hsing-Long Road, Taipei 11696, Taiwan. ${ }^{2}$ Department of Pathology, Taipei Medical University-Shuang Ho Hospital, 291, Zhongzheng Road, Zhonghe District, New Taipei City 23561, Taiwan.

Received: 11 June 2013 Accepted: 8 August 2013

Published: 22 August 2013

\section{References}

1. Downing MT, Hamoudi AB, Besner GE: Brain heterotopia: choristoma of the back. Pediatr Surg Int 1997, 12:183-185.

2. Hori A, Brandis A, Walter GF, Petersen C, Massmann J: Retroperitoneal ectopic neural mass: "abdominal brain"-presentation of two cases and proposal of classification of paraneuraxial neural ectopia. Acta Neuropathol 1998, 96:301-306.

3. Penner $C R$, Thompson L: Nasal glial heterotopia: a clinicopathologic and immunophenotypic analysis of 10 cases with a review of the literature. Ann Diagn Pathol 2003, 7:354-359.

4. Buccoliero AM, Caldarella A, Noccioli B, Fiorini P, Taddei A, Taddei GL: Brain heterotopia in pharyngeal region. A morphological and immunohistochemical study. Pathol Res Pract 2002, 198:59-63.

5. Balci S, Nabaei SM, Ozaltin F, Onol B: Bilateral subpleural ectopic brain tissue in a 23-week-old fetus. Turk J Pediatr 2001, 43:273-275.

6. Hahlbohm AM, Hori A, Hoyer PF, Petersen C: Ectopic neural tissue as an unusual cause of a retroperitoneal tumor. Pediatr Surg Int 1997, 12:66-68.

7. Wan J, Ritchey ML, Muraszko K, Bloom DA: Retroperitoneal neurogenous choristoma. J Urol 1992, 148:1867-1868.

8. Tsapralis D, Charalabopoulos A, Karamitopoulou E, Schizas D, Charalabopoulos K, Liakakos T, Macheras A: Pancreatic intraductal papillary mucinous neoplasm with concomitant heterotopic pancreatic cystic neoplasia of the stomach: a case report and review of the literature. Diagn Pathol 2010, 5:4.

9. Dzodic R, Stanojevic B, Saenko V, Nakashima M, Markovic I, Pupic G, Buta M, Inic M, Rogounovitch T, Yamashita S: Intraductal papilloma of ectopic breast tissue in axillary lymph node of a patient with a previous intraductal papilloma of ipsilateral breast: a case report and review of the literature. Diagn Pathol 2010, 5:17.

10. Rahbar R, Resto VA, Robson CD, Perez-Atayde AR, Goumnerova LC, McGill TJ, Healy GB: Nasal glioma and encephalocele: diagnosis and management. Laryngoscope 2003, 113:2069-2077.

11. Arndt S, Wiech T, Mader I, Aschendorff A, Maier W: Rare extracranial localization of primary intracranial neoplasm. Diagn Pathol 2008, 3:14.

12. Tubbs RS, Kelly DR, Wellons JC 3rd, Blount JP, Oakes WJ, Georgeson K: Ectopic brain tissue in a neonate. Pediatr Neurosurg 2003, 39:136-138.

13. Aboud MJ: Respiratory difficulty caused by an ectopic brain tissue mass in the neck of a two-month-old baby: a case report. J Med Case Rep 2011, 5:220.

14. Bratton $A B$, Robinson SH: Gliomata of the nose and oral cavity; a report of two cases. J Pathol Bacteriol 1946, 58:643-648.

15. Oppelt P, Renner SP, Kellermann A, Brucker S, Hauser GA, Ludwig KS, Strissel PL, Strick R, Wallwiener D, Beckmann MW: Clinical aspects of Mayer-Rokitansky-KuesterHauser syndrome: recommendations for clinical diagnosis and staging. Hum Reprod 2006, 21:792-797.

16. Morcel K, Camborieux L, Guerrier D: Mayer-Rokitansky-Kuster-Hauser (MRKH) syndrome. Orphanet J Rare Dis 2007, 2:13.
17. Gilliam ML, Shulman LP: Tetralogy of Fallot, imperforate anus, and Mullerian, renal, and cervical spine (MURCS) anomalies in a 15-year-old girl. J Pediatr Adolesc Gynecol 2002, 15:231-233.

18. Suri M, Brueton LA, Venkatraman N, Cox PM: MURCS association with encephalocele: report of a second case. Clin Dysmorphol 2000, 9:31-33.

19. Marin-Padilla M: Notochordal-basichondrocranium relationships: abnormalities in experimental axial skeletal (dysraphic) disorders. J Embryol Exp Morphol 1979, 53:15-38.

doi:10.1186/1746-1596-8-141

Cite this article as: Deng and Lee: Multicentric paraspinal neuroglial heterotopia with Müllerian and renal agenesis: a variant of MayerRokitansky-Küster-Hauser syndrome? Diagnostic Pathology 2013 8:141.

\section{Submit your next manuscript to BioMed Central and take full advantage of:}

- Convenient online submission

- Thorough peer review

- No space constraints or color figure charges

- Immediate publication on acceptance

- Inclusion in PubMed, CAS, Scopus and Google Scholar

- Research which is freely available for redistribution

Submit your manuscript at www.biomedcentral.com/submit
C) BioMed Central 